\title{
Research funds new friends in Japan's Diet...
}

Tokyo. Japanese science has received a substantial boost in the second supplementary budget to be announced this year - thanks largely to the efforts of a new generation of politicians who are keen to strengthen Japan's science and technology.

The main goal of the supplementary budget is to stimulate the sluggish Japanese economy. But, like the first such budget, announced in May and primarily designed to cope with the Kobe earthquake disaster (see Nature 375, 169 \& 376, 110; 1995), it also contains hundreds of billions of yen billions of dollars - for science.

Both moves followed lobbying by some comparatively young members of the Liberal Democratic Party (LDP), the strongest party within the ruling coalition. The key politician pushing for these large budgets for science is Koichi Kato, secretary general of the LDP. Kato is second only in power to the party leader Ryutaro Hashimoto, and is said by one official of the Ministry of International Trade and Industry (MITI) to be "very, very keen" on science and technology.

Another supporter of increased science past, senior LDP politicians have tended to spend their energies lobbying for large construction projects and paying little attention to science. But a series of scandals has transspending is Koji Omi also of the LDP. In the

formed Japan's political scene, leading not only to the present coalition government, but also to internal changes in the parties that have allowed younger politicians such as Kato and Hashimoto to come to the fore.

In the latest budget, approved by the Diet in mid-October, the Ministry of Education, Science, Sports and Culture (Monbusho) received an allocation of $¥ 224$ billion yen (US $\$ 2.24$ billion) for the promotion of so-

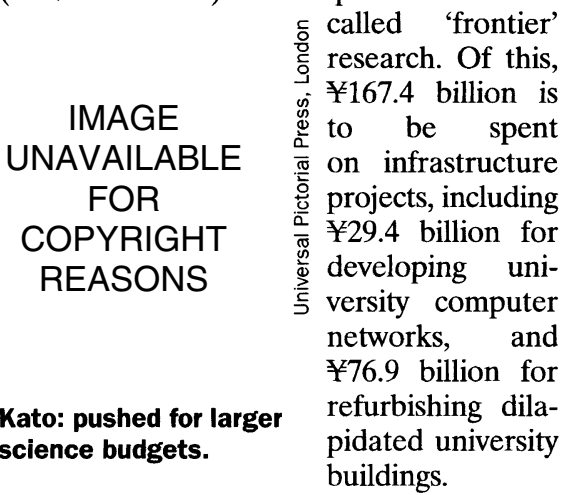

Monbusho's regular system of grants will receive only a small boost of $¥ 3$ billion. But large-scale accelerator projects at the National Laboratory for High Energy Physics in Tsukuba, as well as a large-scale 'helical' fusion device at the National Institute for Fusion Science in Nagoya, will

\section{... but CERN fails to gain extra money}

Tokyo. Japan's high-energy physicists and the Ministry of Education, Science, Sports and Culture (Monbusho) have failed to pull off a double feat in their attempt to obtain further substantial funding for the Large Hadron Collider (LHC) at the European Laboratory for Particle Physics (CERN) in Geneva, Switzerland, in the latest supplementary budget (see above).

Earlier this year, Japan gave CERN a pleasant surprise when it announced plans to contribute $¥ 5$ billion (US\$50 million) towards construction of the LHC (see Nature 375, 169; 1995). Scientists and the ministry had both been hoping to supplement this with a further contribution of $¥ 2$ billion towards a "common fund" being set up for the ATLAS detector on the LHC. CERN has asked both member and nonmember participants to make contributions to the common fund as soon as possible, in addition to their own individual budgets for participation in ATLAS.

Monbusho held preliminary discussions with the Finance Ministry about including the $¥ 2$ billion in last month’s supplementary budget. But, say Monbusho officials, it never got as far as an "official request".

Keisuke Yoshio, Monbusho's coordinator for international programmes in the international science division, says the ministry can still apply for the $¥ 2$ billion at a later stage. One such possibility would be the budget for the fiscal year 1997, requests for which will be made next August. But the ministry had been hoping for a quick promise of the $¥ 2$ billion in order to demonstrate its commitment to CERN and ATLAS.

Meanwhile, the education ministry has made a small budget request of $¥ 92$ million for fiscal 1996 (which begins in April) as a first step towards obtaining a total contribution of several billion yen for ATLAS between now and 2003. A decision on that request will be made by the Finance Ministry and the cabinet at the end of December. Such requests are seldom rejected, although they can be trimmed back.

Masayuki Inoue, director of Monbusho's international science division, who has led the negotiations with CERN, admits that even the ministry was slightly surprised when it won $¥ 5$ billion in the first supplementary budget in May. That budget was a response to the Kobe earthquake disaster, and to explain the windfall for CERN he quotes an old Japanese saying "ten no toki, chinori, hito no wa" - which roughly translates "even when the heavens provide an opportunity, and conditions on the ground are right, human cooperation is the key to success".
David Swinbanks receive a total of $¥ 33$ billion.

Selected laboratories at some of the larger and better-known national universities, designated as 'venture business' laboratories, will receive an extra $¥ 11.1$ billion in addition to the $¥ 14.6$ billion allocated in the earlier supplementary budget.

MITI will receive an $R \& D$ budget of $¥ 35.6$ billion. Of this, $¥ 18.3$ billion will go to the New Energy Development Organization (NEDO), more than half to be spent on a single project aimed at developing ultraadvanced processing technology for the microelectronics industry in which laboratories from both universities and national institutes are expected to participate.

NEDO will use another $¥ 5.1$ billion to continue a grant scheme, inaugurated earlier this year with $¥ 10$ billion from the first supplementary budget (see Nature 377, 378; 1995), which is open to researchers at both universities and national research institutes. Other items in the MITI budget include $¥ 2.6$ billion for recycling and other environmental technologies and $¥ 4.6$ billion for a measurements and standards laboratory.

The Science and Technology Agency (STA) has received $¥ 74.7$ billion, including $¥ 14.9$ billion to accelerate completion of its new synchrotron SPring-8 (see Nature 377, 566 ; 1995) and $¥ 5.1$ billion for competitive grants open to all public sector researchers.

Akisha Arima, former president of Tokyo University and current president of STA's Institute of Physical and Chemical Research (RIKEN), says that the new political climate, in which active politicians are pushing hard for increases in the research budget, make him "very happy" - even though he is concerned that "it may not last". Arima has been campaigning for years for dramatic reform of Japan's university research system, which the large new budgets are helping to achieve. Stephen Barker

\section{AAAS calls for end to 'ex-communists' ban}

Washington. A report from the American Association for the Advancement of Science (AAAS) has called on governments in former communist-ruled countries to end blanket discrimination against academics alleged to have had ties to communism.

The report, released in Washington last week, suggests that so-called 'lustration' (cleansing) laws, which have resulted in large-scale dismissals of university staff in Bulgaria, the Czech Republic and Germany, should only be implemented on a case-bycase basis. The AAAS also calls on postcommunist governments to implement methods of democratic reform "that do not contain repressive elements". 